\title{
Thermomechanical Properties and
} Shape-Memory Behavior of Bisphenol A Diacrylate-Based Shape-Memory Polymers

\author{
David Santiago, Silvia De la Flor, Francesc Ferrando, Xavier Ramis, \\ Marco Sangermano*
}

A series of acrylate-based shape-memory materials are synthesized from bisphenol A diacrylate monomers as crosslinking agents. Networks are synthesized by keeping constant the content of bisphenol A-based crosslinking agent and systematically varying the content ratio of different monofunctional chain builder monomers. The implications of the structure of bisphenol A-based monomers and the chemical structure and content of monofunctional monomers on thermomechanical properties are discussed. Thermomechanical properties are analyzed using dynamic mechanical analyses and mechanical properties are studied at room temperature and at the onset of the glass transition temperature. Shape-memory performances under isothermal and transient temperature conditions are also carried out. Tensile tests show excellent values of stress at break up to 45 and $15 \mathrm{MPa}$ at room and high temperature, respectively. The measurements show excellent shape recovery and shape fixity ratios, $\approx 95 \%$ and $97 \%$, respectively. These materials also show very high recovery velocities under transient temperature conditions, up to $24 \% \mathrm{~min}^{-1}$, and very short recovery times, up to $1.5 \mathrm{~s}$, under isothermal conditions in a water bath. The results confirm that networks synthesized from bisphenol $\mathrm{A}$ crosslinkers are promising shape-memory materials.

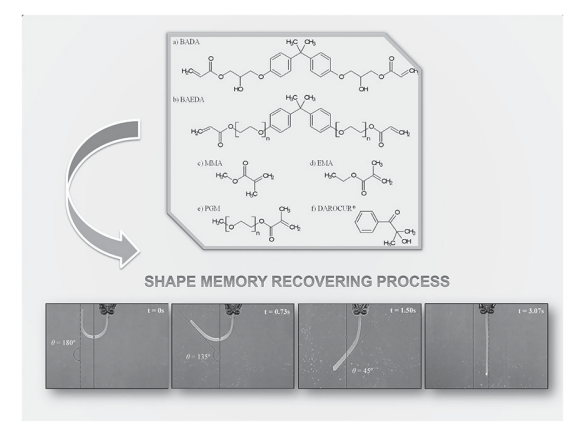

D. Santiago, Dr. S. De la Flor, Dr. F. Ferrando Departament of Mechanical Engineering Universitat Rovira i Virgili

Av. Països Catalans 26, 43007 Tarragona, Spain Dr. X. Ramis

Thermodynamics Laboratory

Heat Engines Department ETSEIB

Universitat Politècnica de Catalunya

Av. Diagonal 647, 08028 Barcelona, Spain

Prof. M. Sangermano

Dipartamento di Scienza Applicata e Tecnologia

Politecnico di Torino

C.so Duca degli Abruzzi 24, 10129 Turin, Italy

E-mail: marco.sangermano@polito.it

\section{Introduction}

Shape-memory polymers (SMPs) are a class of materials that have the capability of changing their shape upon application of an appropriate external stimulus. These polymers can be processed in a permanent or original shape by conventional techniques and then, deformed in a new or temporary shape that can remain stable until the stimulus is applied. ${ }^{[1]}$ The shape changing is usually driven by heat but it can also be driven by light, magnetic field, or an electrical current. ${ }^{[2-4]}$ In the recent years, SMPs have attracted a lot of interest due to their wide range of applications including self-deployable structures for aerospace 
applications, smart fibers, and fabrics for smart clothing, electronics, or biomedical devices. ${ }^{[5-8]}$

Usually SMPs are classified depending on their chemically nature (thermoplastic or thermosets) and transition temperature (glass or melting transition temperature). The most common SMPs are usually thermoplastics due to their high deformability and easy processing, making them suitable for a great variety of potential applications. ${ }^{[9,10]}$ However, in recent years some studies have reported shape-memory thermosets with excellent mechanical and shape-memory properties such as epoxy-based or UVpolymerized acrylate-based shape-memory polymers. ${ }^{[11,12]}$

UV-polymerization is growing in importance due to their wide fields of applications including surface coatings, adhesives, printing inks, or composites materials. ${ }^{[13-16]}$ Radical UV-polymerization possess many advantages in front of traditional thermal curing: faster polymerization rates, lower energy consumption because it is usually carried out at room temperature and it is environmental friendly due to the use of solvent-free formulations. ${ }^{[17]}$

The primary backbone of acrylate-based shape-memory networks are formed through free radical polymerization of crosslinking monomers and pendant segments formed by monofunctional chain builder monomers. ${ }^{[18]}$ Several works have focused on the use of acrylate-based shapememory polymers for biomedical applications due to their high degree of biocompatibility. ${ }^{[19]}$ Smith et al. ${ }^{[20]}$ investigated how the mechanical properties of methacrylate networks are influenced by physiological conditions by using poly(ethylene glycol) dimethacrylate and different monofunctional monomers. Ortega et al. ${ }^{[21]}$ studied the effect that crosslinking and long-term storage have on shape-memory properties of different formulations formed by the copolimerization of tert-butyl acrylate with poly(ethylene glycol) dimethacrylate with different molecular weights. Smith et al. ${ }^{[22]}$ studied the relationship between mechanical properties and chemical structure of materials synthesized from poly(ethylene glycol) dimethacrylate and three different monofunctional monomers deformed in air and under hydrated conditions.

Other works have focused on studying thermal, mechanical, and shape-memory properties of these networks as well as the influence of the functionality and the concentration of the monomers on such properties. Yakacki et al. ${ }^{[23]}$ investigated the influence of the polymer network on free and constrained recovery under isothermal and transient temperature conditions in materials obtained from synthesizing methyl-methacrylate and poly(ethylene glycol) dimethacrylate. Arrieta et al. ${ }^{[12]}$ studied the shape-memory properties of a network formed by benzyl methacrylate and poly(ethylene glycol) dimethacrylate. They programmed the temporary shape at different programming temperatures and performed free and constrained recovery at different heating rates.
Accordingly, acrylate-based shape-memory networks synthesized from poly(ethylene glycol)-based monomers as crosslinking agents are fully characterized and have demonstrated their excellent mechanical and shapememory properties. However, minus work has been done with different crosslinking agents, such as bisphenol A-based diacrylate monomers. Networks formed by this kind of monomers are commonly used in many applications due to their good adhesion, hardness, and thermal and chemical resistance. ${ }^{[24]}$ By substituting poly(ethylene glycol)-based acrylate crosslinkers for bisphenol A-based crosslinkers with higher cohesive energy density (CED), it is expected higher glass transition temperatures as well as an increase of the mechanical properties due to the presence of aromatic rings within the structure. In this sense, this study proposes the use of bisphenol A-based bifunctional monomers as crosslinking agents for shapememory thermosets.

A few works have explored the use of bisphenol A-based crosslinking agents for shape-memory materials. Safranski and Gall ${ }^{[18]}$ studied the effect of chemical structure and crosslinking density on the thermal and mechanical properties of (meth)acrylate networks. The authors proposed different monofunctional monomers as chain builder and different multifunctional monomers as crosslinking agents, including bisphenol A-based monomers. Voit et al. ${ }^{[25]}$ studied the transition of acrylatebased materials from thermoplastic to thermosets in order to obtain high strain shape-memory polymers. For this purpose, these authors suggested to minimize the concentration of bisphenol A ethoxylate di(meth) acrylate crosslinking agent until less than $0.25 \%$. However, it is necessary a further investigation of the implications that the presence of this kind of monomers have on thermomechanical properties and a deep study of the shape-memory properties.

Therefore, in the present study a family of shapememory materials is synthesized from three different monofunctional monomers as chain builders, and two different bisphenol A-based bifunctional monomers as crosslinking agents. The networks are synthesized by keeping the content of crosslinking agent constant and systematically varying the content ratio of different monofunctional monomers. The implications of the chemical structure of bisphenol A-based monomers and monofunctional monomers on the thermomechanical and viscoelastic properties are analyzed and discussed. Tensile tests and shape-memory performances have revealed shape-memory materials with good mechanical properties, both at room and high temperatures, and excellent shape-memory properties with very high recovery and fixity ratios and fast recovery velocities under isothermal and transient temperature conditions. 


\section{Experimental Section}

\subsection{Materials}

Diglycidyl ether of bisphenol A diacrylate (BADA) (Ebecryl 605, Allnex) (based on 75/25 w/w bisphenol A diacrylate/tripropylene glycol diacrylate) with $M_{\mathrm{w}}=500 \mathrm{~g} \mathrm{~mol}^{-1}$ (Figure 1a) and diglycidyl ether of bisphenol A ethoxylate diacrylate (BAEDA) (Sigma-Aldrich) with $M_{\mathrm{n}}=512 \mathrm{~g} \mathrm{~mol}^{-1}$ (Figure $1 \mathrm{~b}$ ) were used as crosslinker agents. Methyl methacrylate (MMA) (Sigma-Aldrich) (Figure 1c), ethyl methacrylate (EMA) (Sigma-Aldrich) (Figure 1d), and poly(ethylene glycol) methylether methacrylate (PGM) (Sigma-Aldrich) with $M_{\mathrm{n}}=475 \mathrm{~g} \mathrm{~mol}^{-1}$ (Figure 1e) were used as monofunctional chain builders. Darocur 1173 (BASF) was used as photoinitiator (Figure 1f).

The CED was calculated for MMA, EMA, and PGM in order to discuss thermal and mechanical properties of the materials prepared. CED parameter characterizes the intermolecular interactions in polymers using the group contributions according to the method outlined by Van Krevelen. ${ }^{[26]}$ The CED values for MMA, EMA, and PGM were 398, 385, and $340 \mathrm{MPa}$, respectively.

Various formulations with different content of each reactant were prepared and are summarized in Table 1 . The formulations were prepared by mixing 50 wt\% of BADA or BAEDA which acted as crosslinker agents and $50 \mathrm{wt} \%$ of a mixture of MMA, EMA, or poly(ethylene glycol) methylether methacrylate which acted as monofunctional chain builders. The content of crosslinking agent was kept constant in both set of formulations in order to avoid the effect of different crosslinking densities within the networks. Preliminary studies concluded that formulations with BADA synthesized with no presence of PGM or with BAEDA synthesized with a MMA:PGM or EMA:PGM ratio of 1:3 were not suitable for shape-memory performances because they showed too high and too low values of stiffness, respectively. The photoinitiator 2-hydroxy-2-methyl-1-phenyl-propan-1-one (Darocur 1173, BASF) was added at a concentration of $2 \mathrm{wt} \%$ of the total formulation weight. The reactants were mixed manually in an opaque plastic vial until fully dissolved and poured in an open mould with dimensions $30 \mathrm{~mm} \times 3.75 \mathrm{~mm} \times 0.75 \mathrm{~mm}$. The polymerization took place by exposing the configuration to UV light (Helios Italquartz) for $2 \mathrm{~min}$ at an intensity of $\approx 100 \mathrm{~mW} \mathrm{~cm}{ }^{-2}$ (measured with an EIT UV-meter) in a nitrogen atmosphere. Finally the samples were polished to obtain the final dimensions for each test.

\subsection{Thermomechanical Characterization}

Thermomechanical properties were measured using a DMA O800 (TA Instruments) equipped with a film-tension clamp. Prismatic rectangular samples of $\approx 20 \mathrm{~mm} \times 2 \mathrm{~mm} \times 0.5 \mathrm{~mm}$ were analyzed at $1 \mathrm{~Hz}, 0.1 \%$ strain, and a heating rate of $3{ }^{\circ} \mathrm{C} \mathrm{min}-1$ from -30 to $150{ }^{\circ} \mathrm{C}$. The glass transition temperature $T_{\mathrm{g}}$, the onset of the glass transition temperature $T_{\mathrm{g}}{ }^{\mathrm{E}^{\prime}}$, and the storage modulus below and above the glass transition temperature were

a) BADA<smiles>C=CC(=O)OCC(O)COc1ccc(C(C)(C)c2ccc(OCC(O)COC(=O)C=C)cc2)cc1</smiles>

b) BAEDA<smiles>C=CC(=O)OCCOc1ccc(C(C)(C)c2ccc(OCCOC(=O)C=C)cc2)cc1</smiles>

c) MMA<smiles>C=C(C)C(=O)OC</smiles>

e) PGM<smiles>C=C(C)C(=O)OCCCOC(C)(C)C</smiles>

d) EMA<smiles>C=C(C)C(=O)OCC</smiles>

f) DAROCUR ${ }^{\circledR}$<smiles>CC(C)(O)C(=O)c1ccccc1</smiles>

Figure 1. a) Chemical structure of bisphenol A diacrylate; b) chemical structure of bisphenol A ethoxylate diacrylate; c) chemical structure of methyl methacrylate; d) chemical structure of ethyl methacrylate; e) chemical structure of poly(ethylene glycol) methylether methacrylate; and f) chemical structure of Darocur 1173.

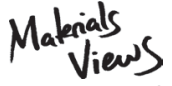


Table 1. Composition of the formulations studied.

\begin{tabular}{llccccc}
\hline Sample & $\begin{array}{c}\text { BADA } \\
\text { [wt\%] }\end{array}$ & $\begin{array}{c}\text { BAEDA } \\
\text { [wt\%] }\end{array}$ & $\begin{array}{c}\text { MMA } \\
\text { [wt\%] }\end{array}$ & $\begin{array}{c}\text { EMA } \\
\text { [wt\%] }\end{array}$ & $\begin{array}{c}\text { PGM } \\
\text { [wt\%] }\end{array}$ \\
\hline 1 & BA-1M-3P & 50 & 0 & 12.5 & 0 & 37.5 \\
2 & BA-2M-2P & 50 & 0 & 25 & 0 & 25 \\
3 & BA-3M-1P & 50 & 0 & 37.7 & 0 & 12.5 \\
4 & BA-1E-3P & 50 & 0 & 0 & 12.5 & 37.5 \\
5 & BA-2E-2P & 50 & 0 & 0 & 25 & 25 \\
6 & BA-3E-1P & 50 & 0 & 0 & 37.5 & 12.5 \\
7 & BAE-2M-2P & 0 & 50 & 25 & 0 & 25 \\
8 & BAE-3M-1P & 0 & 50 & 37.5 & 0 & 12.5 \\
9 & BAE-M & 0 & 50 & 50 & 0 & 0 \\
10 & BAE-2E-2P & 0 & 50 & 0 & 25 & 25 \\
11 & BAE-3E-1P & 0 & 50 & 0 & 37.5 & 12.5 \\
12 & BAE-E & 0 & 50 & 0 & 50 & 0
\end{tabular}

evaluated ( $E_{\mathrm{g}}^{\prime}$ and $E_{\mathrm{r}}^{\prime}$, respectively) (Figure 2). The glass transition temperature was determined from the peak in the loss factor tan $\delta$. The onset of the glass transition temperature $T_{\mathrm{g}}{ }^{\mathrm{E}^{\prime}}$ was determined as the point at which the storage modulus $E^{\prime}$ started to decrease during mechanical relaxation.

\subsection{Fourier Transform Infrared Spectroscopy (FT-IR) Characterization}

Final conversion of each formulation was evaluated by FT-IR. Each formulation was irradiated using a FT-IR Thermo-Nicolet 5700 model. The formulations were coated onto a sample holder $(\approx 50 \mu \mathrm{m})$ and exposed to UV-light at an intensity of $\approx 25 \mathrm{~mW} \mathrm{~cm}^{-2}$. After $30 \mathrm{~s}$ of UV irradiation, the sample was irradiated with IR which analyzed the extend of the reaction and then irradiated again during $30 \mathrm{~s}$ with UV-light. This process was repeated until final conversion. The disappearance of the peak corresponding to acrylate double bond at $1635 \mathrm{~cm}^{-1}$ was monitored and, as the IR absorbance is proportional to the monomer concentration, the final conversion could be obtained.

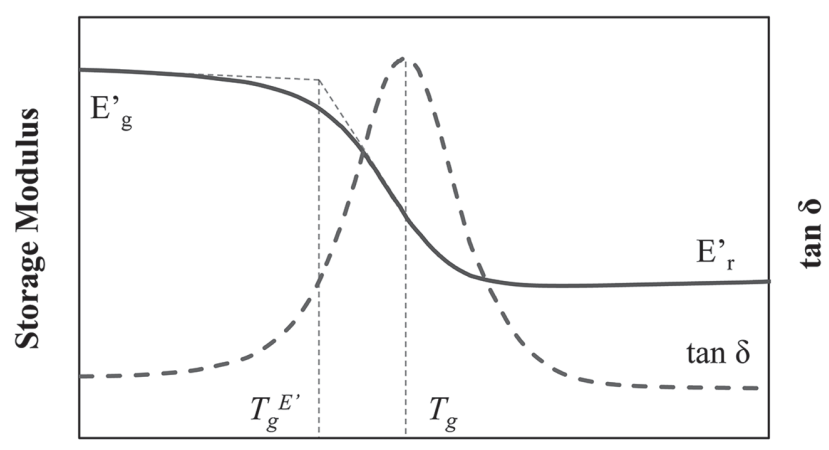

Temperature

Figure 2. Determination of the temperatures $T_{\mathrm{g}}$ and $T_{\mathrm{g}} \mathrm{E}^{\prime}$ from the results obtained with DMA analysis.

\subsection{Mechanical Characterization}

Mechanical properties at room temperature were evaluated using a universal testing machine (Instron 3366) equipped with a $10 \mathrm{kN}$ load cell. Dog-bone shape samples were cut according to ASTM D638 Type IV requirements. Experiments were performed at a crosshead speed of $1 \mathrm{~mm} \mathrm{~min}{ }^{-1}$. Mechanical properties at high temperature were measured using a DMA O800 (TA Instruments) equipped with a film-tension clamp in the force controlled mode. Dog-bone shape samples of $\approx 20 \mathrm{~mm} \times 2 \mathrm{~mm} \times 0.5 \mathrm{~mm}$ were analyzed at $T_{\mathrm{g}}{ }^{\prime}$ at a force rate of $1 \mathrm{~N} \mathrm{~min}^{-1}$. In both experiments, three different samples were used and the average values are shown, and strain was calculated as the total elongation $\left(L_{\mathrm{f}}-L_{0}\right)$ (displacement of the crosshead) with respect to the initial length $\left(L_{0}\right)$ (Equation (1))

$$
\varepsilon(\%)=\frac{L_{\mathrm{f}}-L_{\mathrm{o}}}{L_{\mathrm{o}}} \times 100
$$

\subsection{Shape-Memory Characterization}

The shape-memory properties were measured using a DMA O800 with a force-controlled mode and equipped with a film-tension clamp. Dog-bone shape samples of $\approx 20 \mathrm{~mm} \times 2 \mathrm{~mm} \times 0.5 \mathrm{~mm}$ were used in shape-memory tests. The procedure for imposing a temporary shape to the SMP was a thermomechanical cycle called programming and consisted in various steps (Figure 3 ). The programming began with heating up the sample to the programming temperature $T_{\text {prog }}$ and deforming to a prescribed value of maximum stress $\sigma_{\mathrm{m}}$ at a $1 \mathrm{MPa} \mathrm{min}^{-1}$. The deformation of the sample once had been stretched was $\varepsilon_{\mathrm{m}}$. The next step was cooling down the sample into a temperature below the transition temperature $T_{\text {low }}\left(0^{\circ} \mathrm{C}\right)$ in order to fix the temporary shape. After fixation, the stress was released at the same stress rate of $1 \mathrm{MPa} \mathrm{min}^{-1}$. There was an amount of deformation that the SMP cannot fix and the deformation of the sample after unloading was $\varepsilon_{\mathrm{u}}$. The recovery process was activated by heating up the

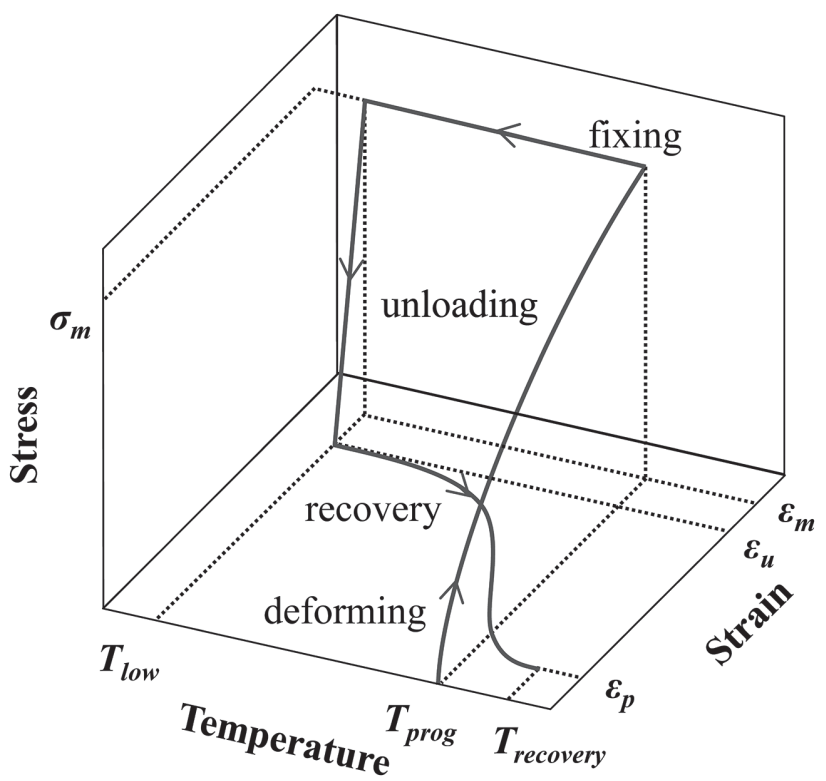

Figure 3. Scheme of the thermomechanical programming. 
sample to a recovery temperature $T_{\text {recovery }}=T_{\mathrm{g}}+10$. The heating rate during shape recovery was $3{ }^{\circ} \mathrm{C} \mathrm{min}^{-1}$. The deformation at the end of programming was $\varepsilon_{\mathrm{p}}$ which is the amount of deformation that the SMP cannot recover. At this point a new cycle began by adjusting the temperature again to $T_{\text {prog. }}$. Three consecutive cycles were performed to each sample.

The programming temperature was selected as the onset of the glass transition temperature $T_{\mathrm{g}} \mathrm{E}^{\prime}$ (Figure 2). According to Yakacki et al. ${ }^{[27]}$ a maximum in the deformability of shape-memory acrylate-based polymer can be obtained at a temperature coinciding with the onset of glass transition temperature.

Every sample was stretched into a determined value of maximum stress $\sigma_{\mathrm{m}}$, corresponding to a $75 \%$ of the stress at break $\sigma_{\mathrm{b}}\left(\sigma_{\mathrm{m}}=0.75 \sigma_{\mathrm{b}}\right)$ in order to perform a comparative study with the same level of load for each sample.

The most significant parameters for quantifying shapememory properties are the shape-recovery ratio $(R r)$ and the shape-fixity ratio $(R f)$. The shape recovery ratio (Equation (2)) quantifies the ability of the SMP to recover its original shape and it was calculated as the total deformation recovered with respect to the maximum deformation reached during the programming. The values of shape-recovery ratio presented correspond to the average value of the three consecutive cycles

$$
R_{\mathrm{r}}(\%)=\frac{\varepsilon_{\mathrm{m}}-\varepsilon_{\mathrm{p}}}{\varepsilon_{\mathrm{m}}} \times 100
$$

The shape fixity ratio, calculated from Equation (3), quantifies the ability of the SMP to fix the temporary shape. It was computed as the deformation after the stress was released with respect to the maximum deformation

$$
R_{\mathrm{f}}(\%)=\frac{\varepsilon_{\mathrm{u}}}{\varepsilon_{\mathrm{m}}} \times 100
$$

Another parameter of interest to evaluate the shape-memory ability is the shape recovery velocity $(\mathrm{Vr})$. The shape recovery velocity quantifies the velocity at which the permanent shape is recovered. $V r$ was calculated as the time interval that it takes from 15 to $85 \%$ of strain recovered (Equation (4))

$$
V_{\mathrm{r}}\left(\% /_{\text {min }}\right)=\frac{\left(\frac{\varepsilon_{\text {rec }, 15 \%}-\varepsilon_{\text {rec }, 85 \%}}{\varepsilon_{\text {rec, }, 15 \%}}\right) \times 100}{\Delta t_{15 \%-85 \%}}
$$

Where $\varepsilon_{\text {rec,15\% }}$ is the deformation corresponding to a shape recovery of $15 \%, \varepsilon_{\text {rec, } 85 \%}$ is the deformation corresponding to a shape recovery of $85 \%$, and $\Delta t_{15 \%-85 \%}$ is the time interval between these two points. The difference between deformations corresponding to a shape recovery of $15 \%$ and $85 \%, \varepsilon_{\text {rec, } 15 \%}-\varepsilon_{\text {rec }, 85 \% \text {, }}$ was calculated with respect to $\varepsilon_{\text {rec, } 15 \%}$ in order to avoid the influence of the maximum deformation on $V_{r}$

Self-deploy shape-memory tests were also performed in order to evaluate the recovery process under isothermal conditions. Prismatic rectangular samples of $\approx 30 \mathrm{~mm} \times 3.75 \mathrm{~mm} \times 0.75 \mathrm{~mm}$ were used. The samples were immersed in a hot water bath at $T_{\text {prog }}=T_{\mathrm{g}}$ of each formulation and held for $30 \mathrm{~s}$. After heating, the samples were deformed into " $U$ " shape (which corresponded to an angle of $\theta=180^{\circ}$ ) with a specially designed device (Figure 4). Then, the samples were immersed in cold water $\left(T_{\text {low }}=10^{\circ} \mathrm{C}\right)$

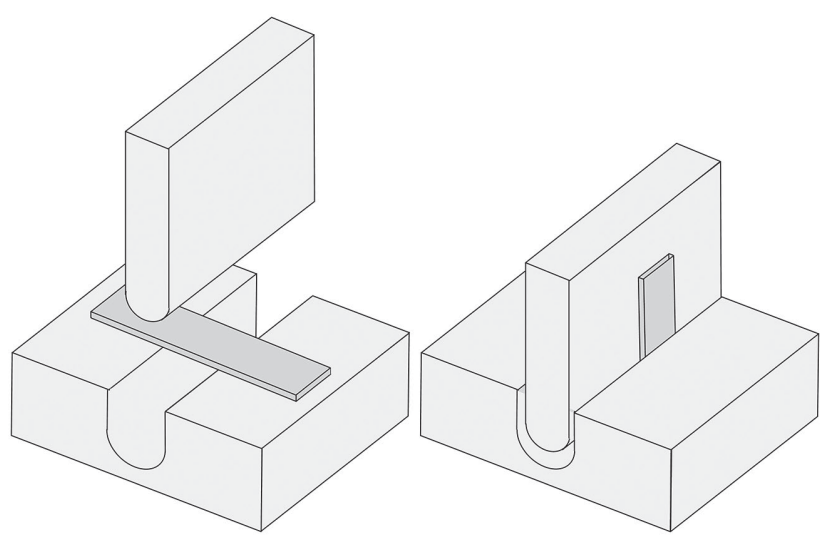

Figure 4. Schematic representation of the deformation of the sample with the U-shaped fixture.

for 5 min while maintaining the "U" shape. In order to evaluate the shape recovery process, the samples were immersed again

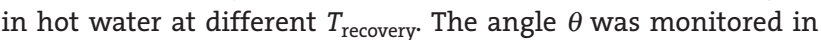
each time of the recovery until the sample reached a complete recovery $\left(\theta=0^{\circ}\right)$ or until finalized the recovery process.

\section{Results and Discussion}

\subsection{Thermomechanical Properties}

Table 2 summarizes the thermomechanical properties of all formulations. The glass transition temperature of the network increases with increasing content of MMA or EMA and decreasing content of PGM. Each set of formulations (either with BADA or BAEDA) have the same backbone because they have the same type and amount of crosslinking agent and thus the pendant side group is the

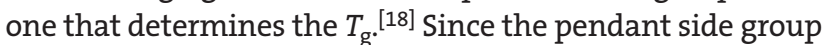
is changed from long and mobile PGM segments to short and rigid MMA or EMA segments, the molecular mobility of the network is restricted and thus causing a delaying in the transition from glassy to rubbery state. This result can be rationalized in terms of CED of the monofunctional monomers. The CED parameter reflects the cohesive strength of the network and, as the $T_{\mathrm{g}}$, is a parameter governing the yield response of glassy networks. ${ }^{[28]}$ The higher CED parameter of monomers MMA and EMA (398 and $385 \mathrm{MPa}$ ) with respect to the CED parameter of the PGM (340 MPa) leads to formulations with a more cohesive structure and thus with higher glass transition temperatures.

The shape of the $\tan \delta$ peak during the material relaxation can also be correlated with its network structure. The peak height is an indicator of the viscous character of the material during the relaxation and the total peak area is related with the total amount of the energy dissipated during relaxation. ${ }^{[29]}$ As can be observed in Table 2 and Figure 5, an increase in the content of PGM causes a broadening of the width of the transition and a lowering of

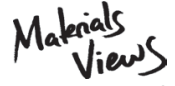


www.mcp-journal.de

Table 2. Thermomechanical results obtained by DMA.

\begin{tabular}{|c|c|c|c|c|c|c|c|c|}
\hline Sample & $\begin{array}{l}T_{\mathrm{g}}{ }^{\mathrm{a})} \\
{\left[{ }^{\circ} \mathrm{C}\right]}\end{array}$ & $\begin{array}{l}T_{\mathrm{g}}^{\mathbf{E}^{\prime}} \\
{\left[{ }^{\circ} \mathrm{C}\right]}\end{array}$ & $\begin{array}{c}\text { FWHM }^{\text {b) }} \\
{\left[{ }^{\circ} \mathrm{C}\right]}\end{array}$ & Tan $\delta$ height & $\operatorname{Tan} \delta$ areac) & $\begin{array}{c}E_{\mathrm{g}}^{\prime \mathrm{d})} \\
{[\mathrm{MPa}]}\end{array}$ & $\begin{array}{c}\left.E_{\mathrm{r}}^{\prime} \mathrm{e}\right) \\
{[\mathrm{MPa}]}\end{array}$ & $E_{\mathrm{g}}^{\prime} / E_{\mathrm{r}}^{\prime}$ \\
\hline BA-1M-3P & 45 & 21 & 32 & 0.53 & 17 & 2125 & 30 & 71 \\
\hline BA-2M-2P & 67 & 44 & 27 & 0.65 & 18 & 2214 & 25 & 87 \\
\hline$B A-3 M-1 P^{f)}$ & 80 & 61 & 22 & 0.90 & 20 & 2741 & 20 & 140 \\
\hline BA-1E-3P & 41 & 15 & 29. & 0.53 & 15 & 1799 & 31 & 59 \\
\hline BA-2E-2P & 53 & 30 & 28 & 0.64 & 18 & 2246 & 27 & 84 \\
\hline$B A-3 E-1 P^{f)}$ & 69 & 50 & 23 & 0.81 & 19 & 2676 & 24 & 111 \\
\hline BAE-2M-2P & 44 & 24 & 22 & 0.77 & 17 & 2244 & 21 & 106 \\
\hline$B A E-3 M-1 P^{f)}$ & 62 & 44 & 21 & 0.86 & 18 & 2750 & 20 & 138 \\
\hline$B A E-M^{f)}$ & 87 & 72 & 19 & 1.01 & 19 & 2712 & 16 & 166 \\
\hline BAE-2E-2P & 33 & 15 & 23 & 0.78 & 18 & 2095 & 23 & 91 \\
\hline$B A E-3 E-1 P^{f)}$ & 50 & 34 & 19 & 0.90 & 17 & 2565 & 21 & 122 \\
\hline$B A E-E^{f)}$ & 70 & 49 & 21 & 0.96 & 20 & 2593 & 17 & 152 \\
\hline
\end{tabular}

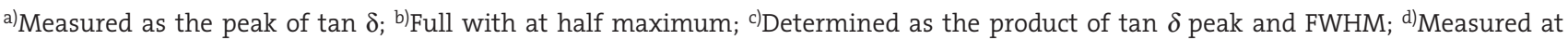

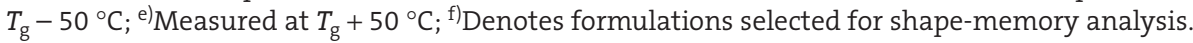

the peak height and area of $\tan \delta$. This trend indicates that the presence of PGM leads to a more heterogeneous network due to the longer length of the polymeric chain of PGM.

The trend of the glass transition temperature contrasts with the trend of the storage modulus at rubbery region $E_{r}^{\prime}$, which decreases with increasing content of MMA or EMA (Figure 6). This trend could be explained in terms of the architecture of the polymer chain between crosslinks. As the content of crosslinking agent is kept near constant, each set of formulations (either with BADA or BAEDA) has the same crosslinking points. Thus, as the content of MMA or EMA increases, the distance between crosslinking points increases and the length of the pendant side group decreases. Consequently the rubbery modulus decreases due to the higher molecular motion of formulations with higher content of MMA or EMA. Other factors may also contribute to this behavior, as the formation of physical crosslinks or molecular interactions between the poly(ethylene glycol) side chains of PGM units.

The storage modulus at glassy region increases as the content of PGM decreases and the content of MMA/EMA increases, according to the lower CED values of PGM.
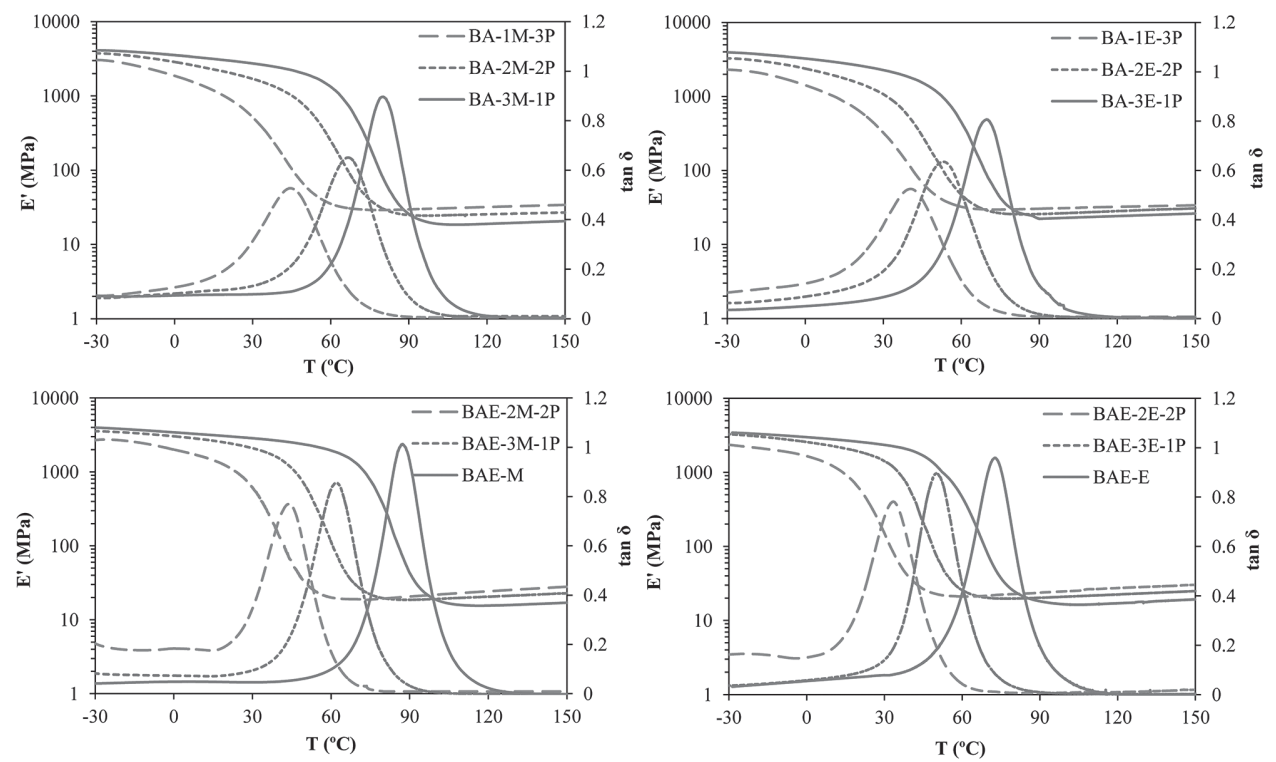

Figure 5. Storage modulus $E^{\prime}$ and $\tan \delta$ as a function of temperature of all formulations. 


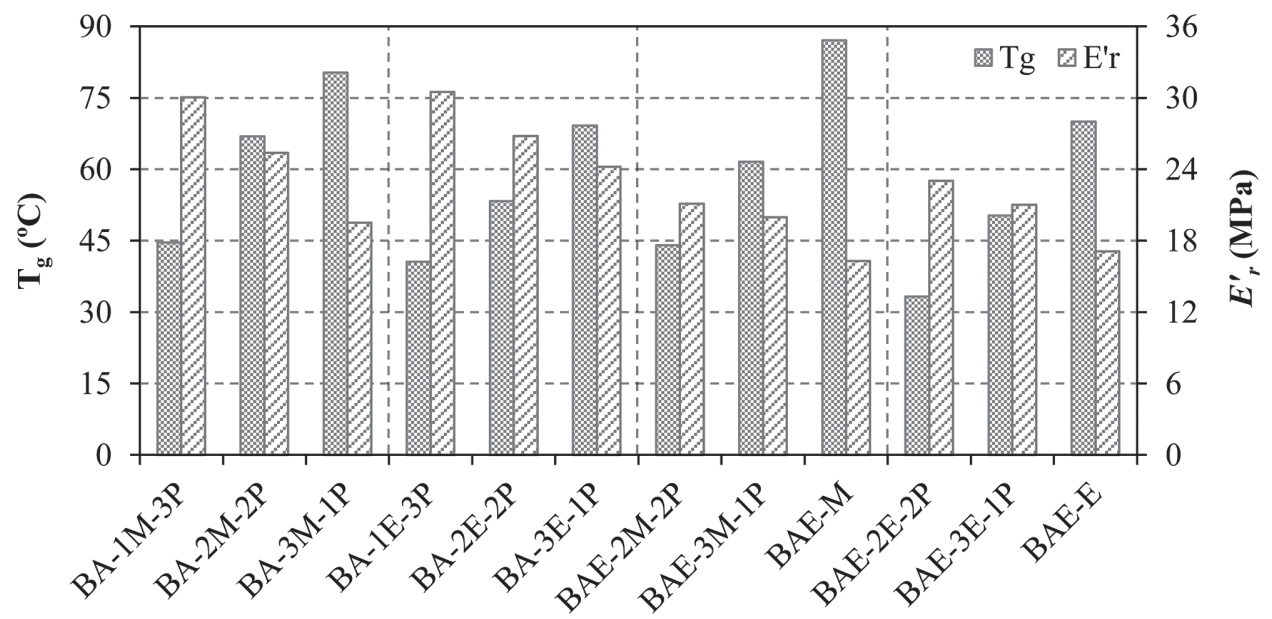

Figure 6. Glass transition temperature $T_{\mathrm{g}}$ and storage modulus $E^{\prime}$ in the rubbery region of all formulations.

Comparing the behavior of formulations with BAEDA and with BADA, the first have lower glass transition temperatures, $\approx 20{ }^{\circ} \mathrm{C}$ in formulations with the same type of monofunctional monomer and content ratio. The shape of the transition indicates a more homogeneous and mobile network with BAEDA than with BADA: the width of the transition is narrower and the peak height is higher (Table 2 and Figure 5). In addition, the storage modulus at rubbery region $E_{r}^{\prime}$ shows lower values with BAEDA than with BADA. The existence of hydrogen-bond interactions in formulations with BADA and the presence of flexible oxyethylene groups in formulations with BAEDA lead to a lower $T_{\mathrm{g}}$ and a more flexible and mobile structure in the relaxed state.

Among all the formulations analyzed in Table 1, only those that show a difference between the storage modulus at glassy and rubbery region around two orders of magnitude were chosen to further studies (denoted by ${ }^{\mathrm{f})}$ in Table 2). This important difference in mechanical properties between the glassy and rubbery states is crucial if a polymer is required to present shape-memory effect. ${ }^{[30]}$ Although the formulation BAE-2M-2P has a properly $E^{\prime}{ }_{\mathrm{g}} / E_{\mathrm{r}}^{\prime}$ ratio, it has low glass transition temperature $\left(44^{\circ} \mathrm{C}\right)$ and cold storage of the temporary shape would be necessary in order to guarantee acceptable fixation. For this reason, these formulations were not selected for further studies.

\subsection{IR Characterization}

In Table 3 are noted the values of final conversion of the selected formulations. The polymerization rate is extremely fast and within the first $30 \mathrm{~s}$ of irradiation the conversion reached values $\approx 90 \%$ in all cases.

\subsection{Mechanical Properties}

Mechanical properties at room temperature $\left(\approx 21^{\circ} \mathrm{C}\right)$ are showed in Table 4 and Figure 7. Figure 7 clearly shows two different behaviors between formulations with BADA and BAEDA. Whereas formulations with BAEDA show a large plateau of plastic deformation with deformations at break of almost 30\% (except in the case of the formulations BAE-E), formulations with BADA barely show plastic deformation, with failure strain $\approx 11 \%$. In the case of ultimate strength, formulations with the same type and content ratio of monofunctional monomers, the ultimate strength is more than a $100 \%$ higher in formulations with BADA than with BAEDA. Properties below the glass transition temperature depend on a combination of factors such as the cohesive forces and presence of local mobility. ${ }^{[31]}$ This different behavior may be attributed to the presence of flexible and mobile oxyethylene groups of BAEDA and the existence of hydrogen-bonds in formulations with BADA.

In both cases, either with BADA or BAEDA as crosslinking agents, the ultimate strength $\sigma_{\max }$ is higher in formulations with MMA than with EMA. This difference is more accused in the presence of PGM (75\% higher in BA-3M-1P than in BA-3E-1P and $100 \%$ higher in BAE$3 M-1 P$ than in BAE-3E-1P) than in formulations without PGM (50\% higher in BAE-M than in BAE-E).

As stated above, mechanical properties depend on different factors and among them the difference between

Table 3. Conversion values of the selected formulations obtained by FT-IR.

\begin{tabular}{|c|c|c|c|c|c|c|}
\hline Sample & BA-3M-1P & BA-3E-1P & BAE-3M-1P & BAE-M & BAE-3E-1P & BAE-E \\
\hline Conversion [\%] & 97 & 98 & 98 & 93 & 100 & 95 \\
\hline
\end{tabular}


www.mcp-journal.de

Table 4. Tensile data at room temperature obtained by uniaxial tensile testing: ultimate strength $\left(\sigma_{\max }\right)$, corresponding strain at ultimate strength $\left(\varepsilon_{\sigma \max }\right)$, stress at break $\left(\sigma_{\mathrm{b}}\right)$, deformation at break $\left(\varepsilon_{\mathrm{b}}\right)$, elastic modulus, and difference between $T_{\mathrm{g}}$ and $T_{\text {room }}$.

\begin{tabular}{lcccccc}
\hline Sample & $\begin{array}{c}\sigma_{\max } \\
{[\mathbf{M P a}]}\end{array}$ & $\begin{array}{c}\varepsilon_{\sigma \max } \\
{[\%]}\end{array}$ & $\begin{array}{c}\sigma_{\mathrm{b}} \\
{[\mathbf{M P a}]}\end{array}$ & $\begin{array}{c}\varepsilon_{\mathrm{b}} \\
{[\%]}\end{array}$ & $\begin{array}{c}\text { Elastic modulus } \\
{[\mathbf{M P a}]}\end{array}$ & $\begin{array}{c}T_{\mathrm{g}}-T_{\text {room }} \\
{\left[{ }^{\circ} \mathbf{C}\right]}\end{array}$ \\
\hline BA-3M-1P & $42.8 \pm 0.4$ & $8.1 \pm 0.8$ & $42.0 \pm 0.4$ & $9.4 \pm 0.9$ & $853.4 \pm 5.2$ & 59 \\
BA-3E-1P & $24.4 \pm 0.2$ & $7.9 \pm 0.9$ & $23.4 \pm 0.1$ & $12.5 \pm 0.2$ & $510.7 \pm 4.9$ & 48 \\
BAE-3M-1P & $20.6 \pm 0.1$ & $6.3 \pm 0.5$ & $18.2 \pm 0.3$ & $18.2 \pm 0.9$ & $477.0 \pm 1.7$ & 40 \\
BAE-M & $45.9 \pm 0.9$ & $6.4 \pm 0.3$ & $39.1 \pm 0.1$ & $25.5 \pm 0.3$ & $948.9 \pm 2.5$ & 66 \\
BAE-3E-1P & $9.7 \pm 0.4$ & $5.2 \pm 0.7$ & $12.4 \pm 0.5$ & $29.0 \pm 0.2$ & $216.6 \pm 4.1$ & 29 \\
BAE-E & $31.4 \pm 0.4$ & $7.2 \pm 0.8$ & $26.3 \pm 0.3$ & $15.7 \pm 0.1$ & $916.3 \pm 5.0$ & 49
\end{tabular}

the test temperature and $T_{\mathrm{g}}$. The observed tendency clearly shows that the strength and elastic modulus increases almost linearly with increasing $T_{\mathrm{g}}-T_{\text {room }}$.

Table 5 summarizes the mechanical properties evaluated at $T_{\mathrm{g}}{ }^{\mathrm{E}^{\prime}}$. All formulations show high values of stress at break, higher than $10 \mathrm{MPa}$ in all cases and up to $15 \mathrm{MPa}$ for the formulation BAE-3E-1P. The values of stress at break at the onset of the glass transition temperature of formulations with poly(ethylene glycol)-based crosslinking agents are usually much lower, which in no case exceed $10 \mathrm{MPa} .^{[19,22,27]}$

The tensile modulus reveals two different behaviors depending on the crosslinking agent used. Formulations with BADA show a tensile modulus $\approx 34 \mathrm{MPa}$ while formulations with BAEDA show tensile modulus $\approx 25 \mathrm{MPa}$. This leads to a higher deformation at break to formulations with BAEDA. This different behavior is due to the presence of oxyethylene groups within the structure of BAEDA and the presence of hydrogen bonds in formulations with BADA. These results correlated well with the results of the mechanical properties evaluated at room temperature, where two different behaviors were also observed between formulations with BADA and BAEDA.

\subsection{Shape-Memory Properties}

In order to perform a comparative study with the same level of load for each sample, every sample was stretched during shape-memory programming to a prescribed maximum stress $\left(\sigma_{\mathrm{m}}\right)$ corresponding to $75 \%$ of the stress at break $\left(\sigma_{\mathrm{m}}=0.75 \sigma_{\mathrm{b}}\right)$. Table 5 presents the prescribed maximum stress and the corresponding maximum deformation reached, $\varepsilon_{\mathrm{m}}$, for each material. Figure 8 shows the average shape-recovery ratio $\left(R_{\mathrm{r}}\right)$ and shape-fixity ratio $\left(R_{\mathrm{f}}\right)$ of three consecutive cycles when programming under these conditions $\left(\sigma_{\mathrm{m}}\right.$ and $\left.T_{\mathrm{g}}{ }^{\prime}\right)$ of each formulation.

All formulations show shape-recovery ratios $\approx 95 \%$, except formulation BAE-3E-1P which shows $91 \%$, and shape-fixity ratios $\approx 97 \%$. Shape-memory properties can also be correlated with thermomechanical properties and network structure. During the programming step, the material can be easily deformed with a significant decrease in the entropy of the system due to chain conformation rearrangement. When the applied external stress is released at low temperature, the lower mobility of the network structure prevents chain rearrangement and holding the remaining deformation. Once the temperature exceeds the $T_{\mathrm{g}}$, the network chains gain sufficient mobility and thus the SMP is able to recover its original shape. Therefore, it can be assumed that network relaxation dynamics is the key parameter governing the recovery process. ${ }^{[32]}$

In the case of formulation BAE-3E-1P, although the tensile test at $T_{\mathrm{g}}{ }^{\mathrm{E}^{\prime}}$ (Table 5) do not reveal significant differences among all formulations, the accumulation of plastic deformation may be the cause of the lower recovery ratio with respect to the rest of formulations.

Figure 9 shows the strain recovered $\varepsilon_{\text {rec }}$ during the recovery stage (Figure 9a) and the shape-recovery velocity $V_{\mathrm{r}}$ (Figure $9 \mathrm{~b}$ ) for all samples. The recovery speed shows very high values for all formulations; it is possible to obtain a $95 \%$ of shape recovery in a few minutes and in a narrow interval of temperatures. As the maximum deformation during stretching has no influence on this parameter, the values and trend of $V_{\mathrm{r}}$ can be explained

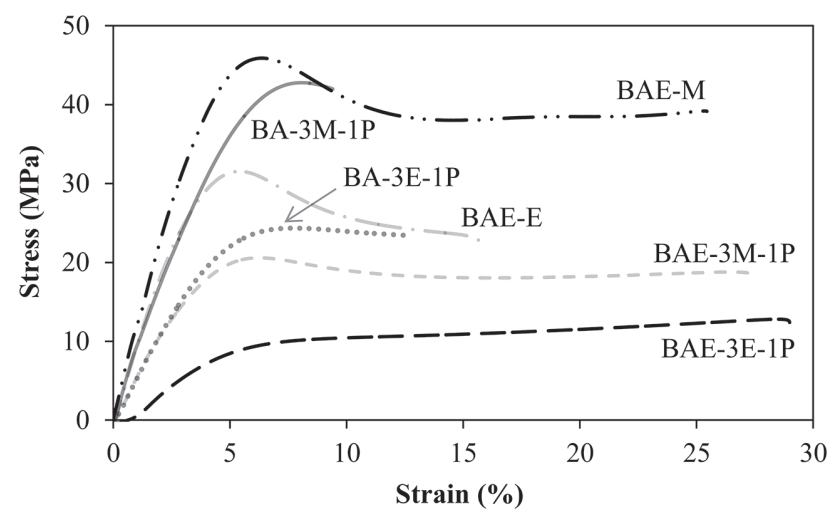

Figure 7. Stress-strain experiments of the selected formulations at room temperature. 
Table 5. Tensile data at $T_{\mathrm{g}}{ }^{\mathrm{E}^{\prime}}$ obtained by DMA: onset of the glass transition temperature $T_{\mathrm{g}}{ }^{\mathrm{E}^{\prime}}$, stress at break $\left(\sigma_{\mathrm{b}}\right)$, deformation at break $\left(\varepsilon_{\mathrm{b}}\right)$, tensile modulus, prescribed stress for shape-memory programming $\left(\sigma_{\mathrm{m}}\right)$, and strain corresponding to $\sigma_{\mathrm{m}}\left(\varepsilon_{\mathrm{m}}\right)$

\begin{tabular}{lcccccc}
\hline Sample & $\begin{array}{c}T_{\mathrm{g}}^{\mathbf{E}^{\prime}} \\
{\left[{ }^{\circ} \mathbf{C}\right]}\end{array}$ & $\begin{array}{c}\sigma_{\mathrm{b}} \\
{[\mathbf{M P a}]}\end{array}$ & $\begin{array}{c}\varepsilon_{\mathrm{b}} \\
{[\%]}\end{array}$ & $\begin{array}{c}\text { Tensile modulus } \\
{[\mathbf{M P a}]}\end{array}$ & $\begin{array}{c}\sigma_{\mathrm{m}} \\
{[\mathbf{M P a}]}\end{array}$ & $\begin{array}{c}\varepsilon_{\mathrm{m}} \\
{[\%]}\end{array}$ \\
\hline BA-3M-1P & 61 & $12.1 \pm 0.9$ & $32.0 \pm 0.2$ & $34.8 \pm 1.2$ & 9.1 & 24.0 \\
BA-3E-1P & 50 & $10.0 \pm 0.5$ & $27.2 \pm 0.3$ & $34.3 \pm 0.5$ & 7.5 & 20.4 \\
BAE-3M-1P & 44 & $11.2 \pm 0.6$ & $41.5 \pm 0.1$ & $25.3 \pm 0.9$ & 8.4 & 31.1 \\
BAE-M & 72 & $13.5 \pm 0.6$ & $50.7 \pm 0.2$ & $24.3 \pm 0.2$ & 10.1 & 38.0 \\
BAE-3E-1P & 34 & $15.4 \pm 0.5$ & $57.0 \pm 0.3$ & $26.6 \pm 0.8$ & 11.5 & 42.8 \\
BAE-E & 49 & $11.8 \pm 0.7$ & $40.4 \pm 0.9$ & $26.9 \pm 0.7$ & 8.9 & 30.3
\end{tabular}

in viscoelastic terms. Although no significant differences were observed in terms of recovery and fixation between the studied formulations, it seems that the recovery velocity is more sensitive to small changes in the thermomechanical properties and network structure between formulations. It can be observed that formulations with BADA show lower values of $V_{\mathrm{r}}\left(\approx 18 \% \mathrm{~min}^{-1}\right)$ than formulations with BAEDA $\left(\approx 22 \% \mathrm{~min}^{-1}\right)$. Formulations with BAEDA have a more homogeneous and mobile network due to the presence of flexible oxyethylene groups, thus it will take shorter to release the stored internal stresses during the recovery process (Table 2 and Figure 5). Formulation BAE-3E-1P presented lower shape-recovery velocity in comparison with the other formulations with BAEDA. The accumulation of plastic deformation during the deformation stage of programming, that also lowered the shape recovery ratio (Figure 8), may also be the cause of the difference on $V_{\mathrm{r}}$ with respect to the rest of formulations with BAEDA.

Formulations BAE-M and BAE-E show the highest values of $V_{\mathrm{r}}\left(21.40\right.$ and $22.62 \% \mathrm{~min}^{-1}$, respectively). The presence of PGM within the networks (Table 2 and Figure 5) leads to more heterogeneous networks, with shorter chain length between crosslinks and long pendant chains that slow down the recovery velocity.

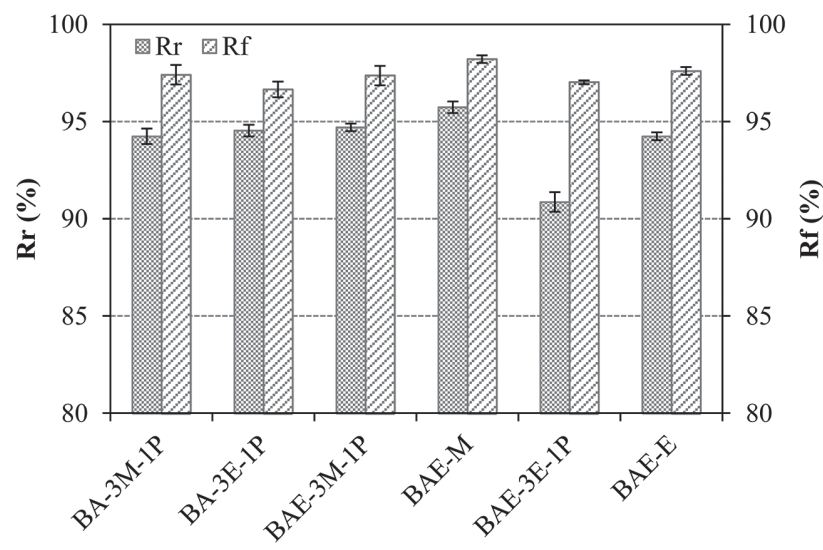

Figure 8. Shape-recovery ratio and shape-fixity ratio of each formulation.
In order to evaluate the recovery velocity under isothermal conditions, self-deploy experiments were performed. The interest of isothermal recovery performances lies in the fact that in many applications the recovery process is triggered at a constant temperature. ${ }^{[33]}$ Results demonstrate the excellent recovery velocities also in isothermal conditions: samples need just a few seconds to reach their original shape and to achieve a complete recovery. Figure 10 shows the recovery process of the formulation BAE-M at $T_{\text {recovery }}=T_{\mathrm{g}}$. The sample only takes $3 \mathrm{~s}$ (including the immersion time) to regain its original shape.
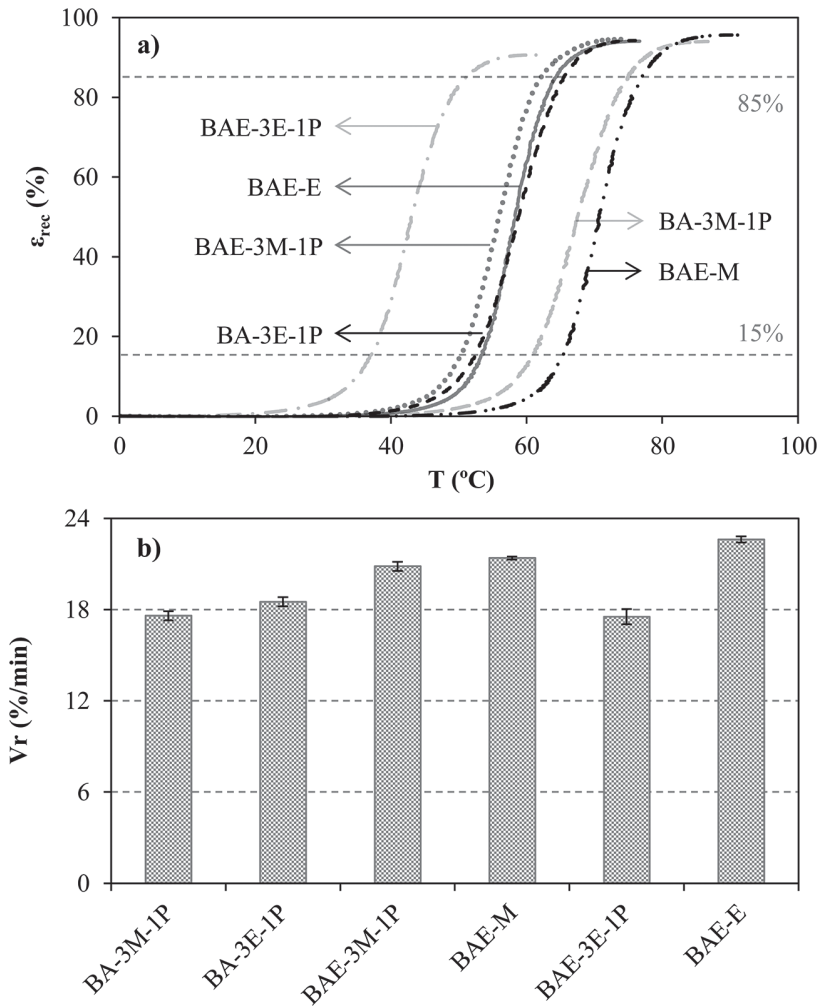

Figure 9. Strain recovered $\varepsilon_{\text {rec }}$ during heating a) and shaperecovery velocity $V_{r}$ b) of all formulations.

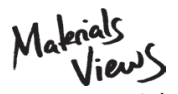



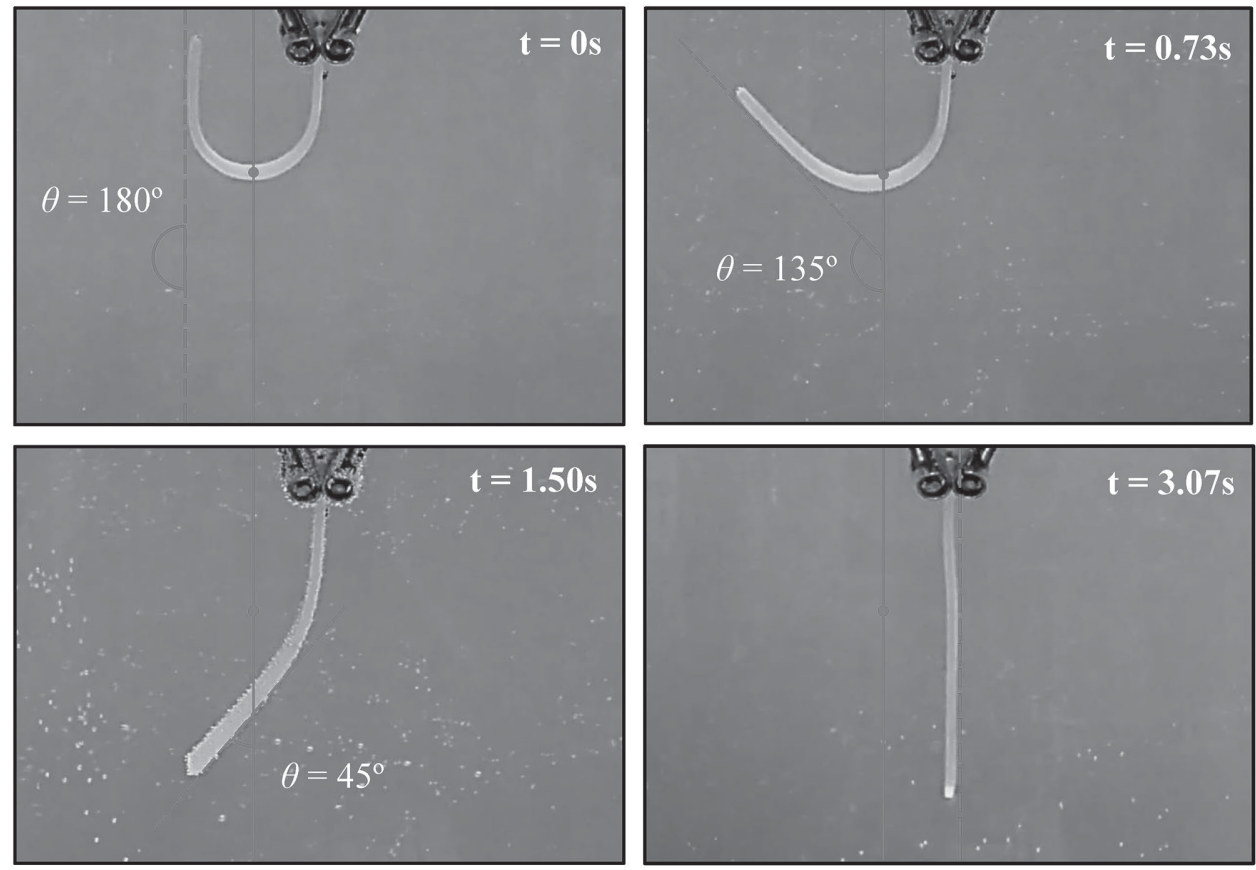

Figure 10. Recovery process of the formulation BAE-M at $T_{\text {recovery }}=T_{\mathrm{g}}$.

Figure 11 shows the recovered angle $\theta$ versus time for each formulation at three different recovery temperatures. The results show extremely short recovery times. Even when the recovery temperature is lower than the glass transition temperature, the majority of the formulations achieve a complete recovery in less than 10 s. Although formulations BAE-3M-1P and BAE-M do not reach a complete recovery at $T_{\text {recovery }}=T_{\mathrm{g}}-10$, the recovery times are quite fast (less than $30 \mathrm{~s}$ ) with corresponding recoveries of $92 \%$.

As expected, it takes less time to achieve a complete recovery with increasing recovery temperature. With an increase in the recovery temperature, the thermal motion of the polymer chains is accentuated and thus the recovery force increases. ${ }^{[34]}$ When $T_{\text {recovery }}=T_{\mathrm{g}}$ and $T_{\text {recovery }}=T_{\mathrm{g}}+10$, the recovery process is almost instantaneous with recovery times $\approx 2.5$ and $1.5 \mathrm{~s}$, respectively.

Three stages of recovery can be distinguished from the slope of the curve in each test. The first stage comprises the recovery from $180^{\circ}$ to $150^{\circ}$, the second stage comprises from $150^{\circ}$ to $30^{\circ}$, and the third one comprises from $30^{\circ}$ until final recovery. During the first stage, the recovery process is triggered and friction between polymer chains is causing a relatively low recovery velocity. In the second stage, the gradual arrangement of segments reduces the friction and thus the slope of the curve increases. In the last stage of recovery the slope of the curve reduces significantly due to the most of the constrained force has been released. Other authors studied the isothermal recovery process and highlighted the presence of various zones during the recovery. ${ }^{[35-38]}$ However, their results are not comparative because in the present work the use of a hot water bath entails different heat transfer between the environment and the samples.

At $T_{\text {recovery }}=T_{\mathrm{g}}-10$ it can be observed differences on the slope of the curves between formulations, especially in formulations BAE-3M-1P and BAE-M. Below the glass transition temperature, the molecular motion are restricted, thus the differences can be attributed to greater difficulty of these formulations in releasing internal stress due to the network architecture. With $T_{\text {recovery }} \geq T_{\mathrm{g}}$ differences in recovery velocity between formulations become less significant and only during the third stage can be observed slight differences in the recovery time. In the case of $T_{\text {recovery }}=T_{g}+10$, the differences between formulations are less than $0.5 \mathrm{~s}$ and all of them achieved complete recovery $\approx 1.5 \mathrm{~s}$.

\section{Conclusions}

A series of acrylate-based shape-memory thermoset materials were synthesized using bisphenol A-based crosslinking agents and different monofunctional monomers as chain builders. Thermal, mechanical, and shape-memory properties were systematically studied and the results were discussed.

The thermomechanical measurements revealed a more heterogeneous network and lower glass transition temperatures with increasing content of PGM and decreasing content of MMA or EMA. Formulations 

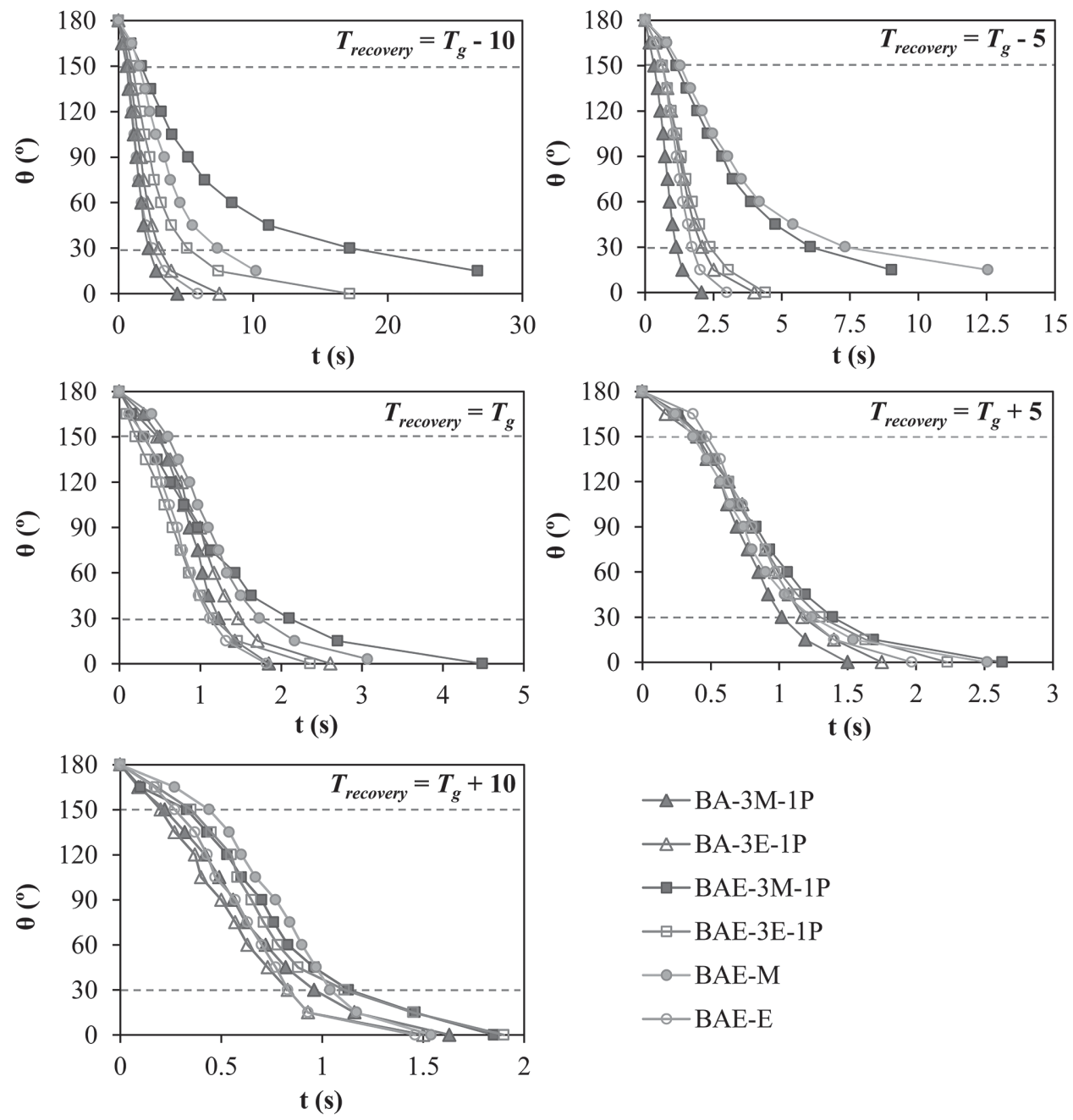

Figure 11. Recovered angle as a function of time of each selected formulation and at different $T_{\text {recovery. }}$

with BAEDA showed lower glass transition temperatures and more homogeneous networks than formulations with BADA. The thermomechanical properties of acrylate-based shape-memory thermosets can be tuned according to the CED parameter at the monofunctional monomers and the rigidity of the crosslinking agent used.

Mechanical properties at room temperature showed two different behaviors: formulations with BAEDA showed a large plateau of plastic deformation with failure strains of almost $30 \%$ than formulations with BADA, with failure strains $\approx 11 \%$. At the programming temperature $T_{\mathrm{g}} \mathrm{E}^{\prime}$, all formulations showed high values of stress at break higher than $10 \mathrm{MPa}$ and up to $15 \mathrm{MPa}$. Formulations with BAEDA showed lower tensile modulus than formulations with BADA and thus higher failure strains due to the presence of mobile oxyethylene units in BAEDA and the existence of hydrogen-bond interactions in formulations with BADA.
Shape-memory properties showed very good values of shape recovery and shape fixity ratios $\approx 95 \%$ and $97 \%$, respectively. These materials showed very fast recovery velocities in transient temperature conditions (up to $24 \% \mathrm{~min}^{-1}$ ) and very short recovery times in isothermal conditions (up to $1.5 \mathrm{~s}$ ).

In accordance with these results, acrylate-based shapememory networks synthesized from bisphenol A-based crosslinking agents are promising shape-memory materials that combine excellent mechanical properties and with very high recovery and fixity ratios as well as very fast recovery velocities.

Acknowledgements: The authors would like to thank MICINN (MAT2014-53706-C03-01 and MAT2014-53706-C03-02) for its financial support.

Received: July 20, 2015; Revised: September 25, 2015; Published online: ; DOI: 10.1002/macp.201500261

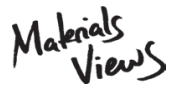

www.MaterialsViews.com
Macromol. Chem. Phys. 2015, DOI: 10.1002/macp.201500261

(c) 2015 WILEY-VCH Verlag GmbH \& Co. KGaA, Weinheim 
Keywords: acrylate; bisphenol A; isothermal; mechanical properties; shape-memory polymers

[1] A. Lendlein, S. Kelch, Angew. Chem. Int. Ed. 2002, 41, 2034.

[2] J. S. Sodhi, P. R. Cruz, I. J. Rao, Int. J. Eng. Sci. 2015, 89, 1.

[3] D. Yang, W. Huang, X. He, M. Xie, Polym. Int. 2012, 61, 38.

[4] S. Chen, S. Yang, Z. Li, S. Xu, H. Yuan, S. Chen, Z. Ge, Polym. Compos. 2015, 36, 439.

[5] Y. Liu, H. Du, L. Liu, J. Leng, Smart Mater. Struct. 2014, 23, 023001.

[6] A. Gugliuzza, E. Drioli, J. Membr. Sci. 2013, 446, 350.

[7] J. Reeder, M. Kaltenbrunner, T. Ware, D. Arreaga-Salas, A. Avendano-Bolivar, T. Yokota, Y. Inoue, M. Sekino, W. Voit, T. Sekitani, T. Someya, Adv. Mater. 2014, 26, 4967.

[8] K. J. Cha, E. Lih, J. Choi, Y. K. Joung, D. J. Ahn, D. K. Han, Macromol. Biosci. 2014, 14, 667.

[9] K. K. Julich-Gruner, C. Löwenberg, A. T. Neffe, M. Behl, A. Lendlein, Macromol. Chem. Phys. 2013, 214, 527.

[10] G. J. Berg, M. K. McBride, C. Wang, C. N. Bowman, Polymer 2014, 55, 5849.

[11] D. Santiago, X. Fernández-Francos, F. Ferrando, S. De la Flor, J. Polym. Sci., Part B: Polym. Phys. 2015, 53, 924.

[12] J. S. Arrieta, J. Diani, P. Gilormini, J. Appl. Polym. Sci. 2014, 131, 39813.

[13] R. Bongiovanni, G. Malucelli, M. Sangermano, A. Priola, Macromol. Symp. 2002, 187, 469.

[14] P. Puomi, H. M. Fagerholm, A. Sopanen, Anti-Corros. Methods Mater. 2001, 48, 160.

[15] M. Sangermano, M. Sturari, A. Chiappone, I. Roppolo, Macromol. Mater. Eng. 2015, 300, 340.

[16] R. Nazar, S. Ronchetti, I. Roppolo, M. Sangermano, R. M. Bongiovanni, Macromol. Mater. Eng. 2015, 300, 226.

[17] M. Sangermano, N. Razza, J. V. Crivello, Macromol. Mater. Eng. 2014, 299, 775.

[18] D. L. Safranski, K. Gall, Polymer 2008, 49, 4446.

[19] K. Gall, C. M. Yakacki, Y. Liu, R. Shandas, N. Willett, K. S. Anseth, J. Biomed. Mater. Res., Part A 2005, 73, 339.
[20] K. E. Smith, S. S. Parks, M. A. Hyjek, S. E. Downey, K. Gall, Polymer 2009, 50, 5112.

[21] A. M. Ortega, C. M. Yakacki, S. A. Dixon, R. Likos, A. R. Greenberg, K. Gall, Soft Matter 2012, 8, 7381.

[22] K. E. Smith, J. S. Temenoff, K. Gall, J. Appl. Polym. Sci. 2009, 114, 2711.

[23] C. M. Yakacki, R. Shandas, D. Safranski, A. M. Ortega, K. Sassaman, K. Gall, Adv. Funct. Mater. 2008, 18, 2428.

[24] C.-H. Park, S.-W. Lee, J.-W. Park, H.-J. Kim, React. Funct. Polym. 2013, 73, 641.

[25] W. Voit, T. Ware, R. R. Dasari, P. Smith, L. Danz, D. Simon, S. Barlow, S. R. Marder, K. Gall, Adv. Funct. Mater. 2010, 20, 162.

[26] D. W. van Krevelen, Properties of Polymers, Elsevier, Amsterdam 1972.

[27] C. M. Yakacki, S. Willis, C. Luders, K. Gall, Adv. Eng. Mater. 2008, 10, 112.

[28] A. J. Lesser, K. J. Calzia, J. Polym. Sci., Part B: Polym. Phys. 2004, 42, 2050.

[29] X. L. Wu, S. F. Kang, X. J. Xu, F. Xiao, X. L. Ge, J. Appl. Polym. Sci. 2014, 131, 40559.

[30] C. Liu, H. Qin, P. T. Mather, J. Mater. Chem. 2007, 17, 1543.

[31] J. P. Pascault, H. Sautereau, J. Verdu, R. J. J. Williams, Thermosetting Polymers, Marcel Dekker, New York 2002.

[32] J. Diani, P. Gilormini, C. Frédy, I. Rousseau, Int. J. Solids Struct. 2012, 49, 793.

[33] C. Azra, C. J. G. Plummer, J.-A. E. Månson, Smart Mater. Struct. 2011, 20, 082002.

[34] D. Zhang, Y. Liu, K. Yu, J. Leng, J. Intell. Mater. Syst. Struct. 2011, 22, 2147.

[35] Y. Liu, C. Han, H. Tan, X. Du, Mater. Sci. Eng. 2010, 527, 2510.

[36] S. Pandini, F. Bignotti, F. Baldi, S. Passera, J. Intell. Mater. Syst. Struct. 2013, 24, 1583.

[37] M. Fan, H. Yu, X. Li, J. Cheng, J. Zhang, Smart Mater. Struct. 2013, 22, 055034.

[38] M. Fan, J. Liu, X. Li, J. Zhang, J. Cheng, J. Polym. Res. 2014, 21, 376. 